\title{
Our High Prices-Have They Come to Stay?
}

\author{
Professor Irving Fisher's Forecast and Advice to Business Men
}

By Alfred J. Lotka

B USINESS conditions are determined in part by the crops, the discovery of new gold fields, the existence of a state of war and the consequent upheaval in demand and supply along abnormal lines, and so forth.

On the other hand certain psychological factors have a large influence upon our economic system. Overconfidence and a somewhat exaggerated spirit of enterprise and activity are the invariable attendants of the upward movement preceding the sudden descent of a so-called economic crisis, just as despondency and so-called economic crisis, just as despondency and
collapse of confidence form part of the phenomenon of the crisis itself. In such cases it is usually difficult or impossible clearly to separate cause and effect. The psychological condition is no doubt partly caused by the existing objective state of affairs; but in turn the frame of mind of the people exerts a reflex influence and affects the objective factors of trade.

All this is perfectly natural. The purpose or function of our mind is to enable us to adapt ourselves to circumstances and to adapt the external world to our needs. Harm arises only when we proceed under mistaken impressions. That under certain conditions we should retrench in our constructive activities is sound business; where we are liable to err is in misjudging when conditions call for such retrenchment or when they justify expansion.

There are indications that our economic system is at the present time suffering more or less acutely from such misjudgment.

In many quarters production is held up, business is deferred, in the expectation that presently a fall in prices will offer more advantageous conditions for purchasing materials and labor; or, construction work is delayed out of solicitude lest a fall in prices should leave the investor with property on his hands which he will not be able to dispose of profitably. There is in many fields a willingness to sell but much hesitation in buying.

The fundamental cause seems to be largely psychological-the recollection of pre-war prices, and the tacit assumption that they represent in some obscure sense "normal" prices, towards which we shall ultimately revert.

Note that this conviction is not held without partiality. As Prof. Irving Fisher of Yale University points out, many manufacturers think that prices must come down, including the price of labor. come down, including the price of labor.
But suggest to them that they make a beginning by lowering their prices, and immediately they are ready with a dem. onstration that their prices can not come down, and that they can not pay lower wages.

The fact is that in this latter contention they are probably substantially right. Where they are at fault is in supposing or maintaining that their case is peculiar. While here and there in special departments there may be While here and there in special departments there may be fluctuations downward as well as upward, the present
high tide in the general price level is probably due to high tide in the general price level is probably due to fundamental causes which are not likely to be removed fessor Fisher, addressing a conference of Governors and Mayors assembled at the White House, expressed his view of the situation as view of

"The fundamental practical question confronting business men is whether the general level of prices is going to fall. In my opinion it is not going to fall much, if at all. We are on a permanently higher price level, and the sooner the business men of the country take this men of the country take this
view and adjust themselves view and adjust themselves
to it, the sooner will they save themselves and the nation from the misfortune which will come if we persist in our present false hopes."

In order to understand the situation it is necessary to form a definite idea regarding the way in which the genera price level is affected by the total amount of currency that is in circulation. It will assist us in gaining an understanding of this matte if we consider first of all an ideal simple case. W can afterwards fill in the details corresponding more closely to actual conditions.

The simple case which we shall first consider is that of a community in which all payments are made in one kind of currency, say gold, and in which there are no redit transactions.

In order to deal in round numbers, let us suppose that in this community there are in circulation 50,000 ounces of gold which in .our coinage represent about one million dollars.

Each gold dollar (i. e., 1/20 of an ounce of gold), in the course of the year, changes hands a number of times, once at each purchase or sale in which it is used for payment.

For example, let us suppose that each ounce of gold changes hands, on an average, 25 times in a year.

At each sale a certain number of gold dollars pass in one direction, and a certain number of pounds of various goods pass in the opposite direction.

The total number of such passages from hand to hand of a gold dollar within a year is evidently the product of $\$ 1,000,000$, the total gold in circulation and 25 , the number of imes each dollar changes hands within a year, making a product of 25 million. On the other hand there is a certain definite number of pounds of goods bought and sold, which are paid for by those 25 million dollars. Supposing for example that 1,000 for example that 1,000
million pounds (one
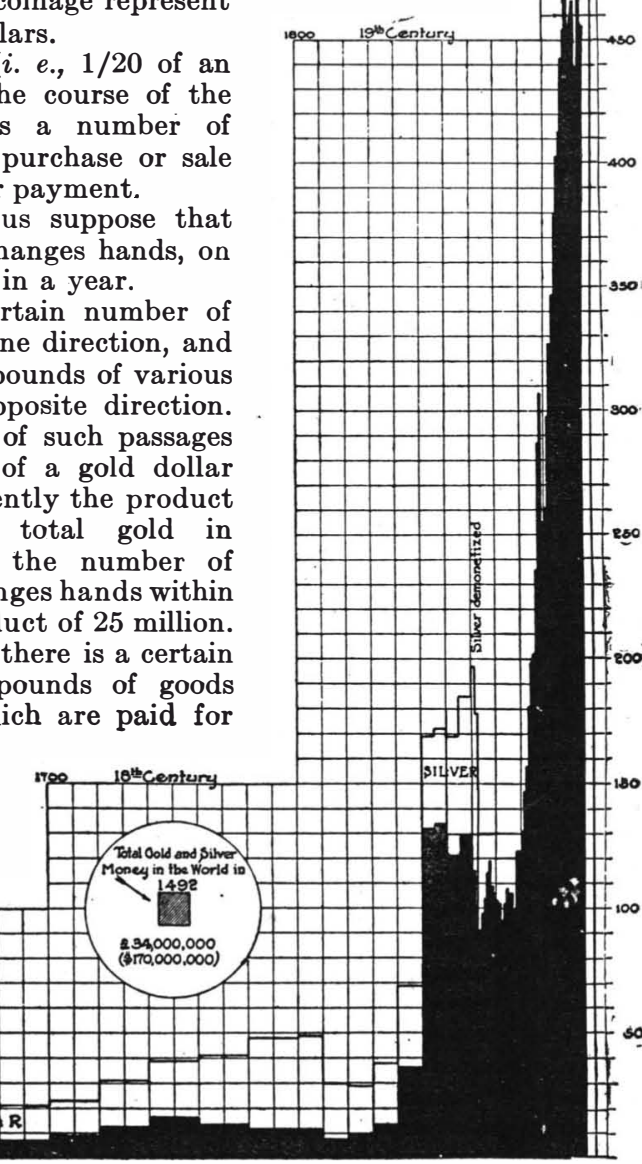

oduction of gold from the discovery of America to the close of the year 1918, also production of silver until demonetized in 1873 billion pounds) of goods change hands in the course of the year, then the average price per pound will be $25 / 1,000$ of a dollar, or $21 / 2$ cents.

Now suppose that all other conditions remain unchanged, but that by some means or other we are able to just double the amount of gold in circulation. In these new circumstances 50 million dollars will pay for the same 1,000 million pounds of goods. The price pe pound, on an average, will now be^five cents, just twice what it was before.



Graphic representation showing the relation between total money in circulation, total bank deposits, velocity of circulation, total trade, and general price level
It will be seen, therefore, that, if in such a community as we have been considering, the total amount of currency in circulation is increased, while other conditions proportion of the increase in the amount of circulating medium of exchange.

Suppose that the doubling of the gold dollars is carried out quite impartially. Each man would suddenly have twice as much money in his pocket as before. At the same time all prices would be doubled. Evidently this would make absolutely no difference in the general economic status of the individual in the community. It is only if the readjustment takes place unevenly that the change causes more or less acute discomfort and suffering to some, while it brings profit to others. In point of fact this is always the case in actual practice, owing to the effect of long time contracts and the inertia of law and custom

In practice, of course, it will never happen that a change in the amount of currency in circulation takes place uneconomic factors. But the effect of the change in the amount of currency in circulation will be essentially the same, though the influence of other factors (such as an increase or decrease in production of commodities) may be superimposed upon that of the change in circulating medium, so as either to reinforce its effect or to mask it more or less completely.

Now in a modern community there are tion made from other coin affect the argument, so far as the United States is concerned, because their total value is but a small fraction of that of the gold in circulation, and their issue and exchange value is fixed by law in terms of gold.

The situation is very different in the case of certain forms of paper currency. Since 1914 Federal Reserve Notes and National Bank Notes amounting in the aggregate to a large value have been issued, which are but partially covered by gold. That portion of the paper currency thus issued,
which is not covered by gold, represents so much increase in our total money in circulation." Another factor which exerts a very important influence on the purchasing power of the gold dollar is the habit or custom established to a greater or less extent in modern civilized countries, and in particular in our United States, of carrying bank deposits subject to check. Such desposits, formed in part of promissory notes secured by various forms of a non-negotiable property, virtually convert such property into liquid, circulating currency. Using again the words of Prof. Irving Fisher:

"To put it crudely, banking is a device for coining into dollars land, stoves, and other wealth not generally exchangeable."

The effect of an increasing prevalence of payment by check is very much the same as if the amount of gold in circulation were increased: Taken by itself, that is to say, in the absence of any compensating changes, it is bound to produce a rise in the general price level. Similar remarks apply to the practice of trading on the basis of book credit, since this tends to create offsetting

*The recent issue of Federa Reserve Bank Notes does not represent any expansion of our currency, since they were merely which were retired. 
debts, which can be partially cancelled without money changing hands. This again is virtually equivalent to the effect of increasing the amount of money in circulation and tends to bring about a rise in the general price level.

The relation between the principal factors thus affecting the general price level is shown graphically in one of our illustrations.

The upper one of the three diagrams represents conditions in 1896. The money in circulation at that timie was 88 bellion dollars, that is to say, each dollar changed hands 18.8 times in a year. This fact is represented in the drawing by a money bag suspended from the scale arm at a point corresponding to 18.8 .

Similarly a bankbook suspended at a point 36.6 indicates that in $1896,2.71$ billion dollars of bank deposits circulated with a velocity of 36.6 per annum for each dollar.

These two factors are balanced on the right hand side of the scale by a certain quantity of all kinds of goods, multiplied by the lever arm, which here represents the price per unit, expressed in percentages of the 1909 prices. It will be understood that the ordinary principles of the lever are assumed; the leverage equals weight multiplied by inltipled by distan are similarly drawn, but the corresponding figures here are:



These horses had never worked tandem before, yet in ten minutes they were United Kingdom.

Another factor which would tend to lower our price courfow of gold to Europe and to othe countries. But we are now the creditors of Europe and money will flow towards us rather than out of our borders. Nor can we figure with any degree of confidence n the introduction of low-priced goods from Europe when normal trade is reëstablished, and look for a when normal trade is reestablished, and look fo

"We are on a new price level, which will be found a tubborn reality. Business men are going to find out that the clever man is not the man who waits, but the one who finds out the new price facts and acts accordingly."

\section{Taking the Plod Out of Plowing}

\section{By C. E. Gapen}

A $S$ man's first assistant the horse has naturally been the subject of numerous investigations and experiments. We have studied his family connections clear back to the time when he had a number of toes and was about the size of a tomcat; but until recently very little progress had been made in studying the connection between the horse and the plow and various other farm implements.

The machines have been improved rapidly and the horse himself has been developed to the drafter that tips the scales at more than a ton; but the ways of applying the power of the improved horse to the improved machine have remained much the same. However the last two years have seen some developments that should mark an epoch in the application of animal power to farm operations.

In the fall of $1917 \mathrm{Mr}$. Wayne Dinsmore secretary of The Percheron Society of America, the largest horse recording association in the country, made some

Currency in circulation.

1914

Velocity of circulation. .................... 17

Bank deposits.

Velocity of circulation.

General price level, expressed in per.....

ages of that in 1919 .

*In billions of dollars.

1918 to even higher levels in Europe than they have here 2.46 30 $46.8 \quad 95.6$ 198

How does all this apply to the present conditions in the United States?

Over one billion dollars in gold has come into this country from abroad since 1914. On June 30th, 1918, the portion of the gold reserve of porthe the Federal Reserve banking system which supported national bank deposits and Federal reserve notes was three times as large as the gold reserves under the old national banking system on June 30th, 1914. During the same period credit instruments (demand deposit and notes) increased about twofold. There is at present a surplus of about 700 million dollars over the legally required gold reserves, and on a conservative estimate this would be sufficient to support a future expansion of 50 per cent in our credit instruments.

These factors in themselves go a long way to account for the present high prices, and do not point toward any probable fall of level.

Such a fall might be induced or aided by a return of gold from reserves into circulation. But experience elsewhere and in the past makes such return appear extremely improbable; the habit of carrying gold
The reconstruction and rehabilitation of devasted regions will call for loan issues and for extension of bank credits. Our Liberty bonds furnish unrivaled security for further borrowings from banks for commercial purposes, and will continue to exert their credit-expanding effect until redeemed by the Government.

Any attempt to reduce bank credit will meet with strenuous opposition. The hostile attitude of labo toward lowering of wages will deter legislators and bankers from any organized policy of contraction.

Most important of all, perhaps, will be the effect of of plowing, by making it possible to
of horses, in tandem team formation

expanding credit in Europe and elsewhere outside our boundaries. The needs of the war have taught the countries of Europe the uses of deposit banking. In China and India also the system is growing. The result will be much the same as if a new source of gold had been found.

The net conclusion seems to stand out clear: All indications are that we may look for little if any fall in the general price level in the near future; that on the contrary we may expect a rise to continue for a conciderable time to come. To sum up in the words of Professor Fisher: investigations that proved to his satisfaction that a large percentage of the farmers in the United States were not getting enough work done per man nor per horse. He found that New England farmers were plowing one acre day on the average Ohio and Pennsylvania farmers from two to two ai rom two to two and and the farmers in the big wheat-growing regions of Oregon and Idaho eight and a half acres a day per man. For this gradua mprovement in results from East to West, the explanation may be found almost entirely in the number of horses worked by one man and in the hitches used.

The result of this looking around has been a development of hitching appliances that should have a pline able effect on the future of the heavy horse. The Percheron Society prevailed upon cheron Society prevailed upon
the University of Illinois to try out experimentally different sized teams and various ways of hitching them to farm implements, and last year Prof. E. A. White of the Farm Mechanics Department made thorough tests
of all known hitches and of some that had not been of all known

It has been customary when four horses or more were worked together on a plow to hitch them abreast, and because they had to be kept off the plowed ground the team was thrown over to one side creating what is known as "side draft." The side draft when four horse are hitched abreast to a plow averages about 25 per cent. And side draft is all waste. It is pull axerted in direction from that in which the implement is supposed (Continued on page 22)

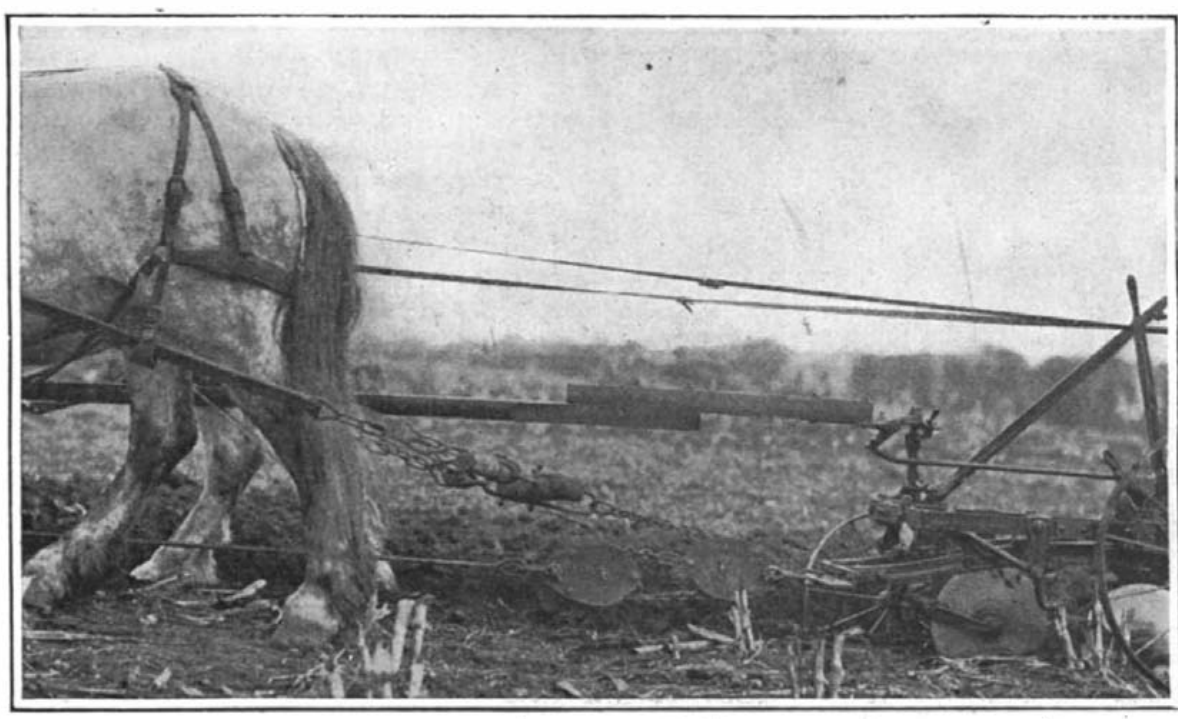

Two single pulleys used when one team is pulling against two. The pulleys are-light there is no need for weights to regulate the angle of traces to the wheelers

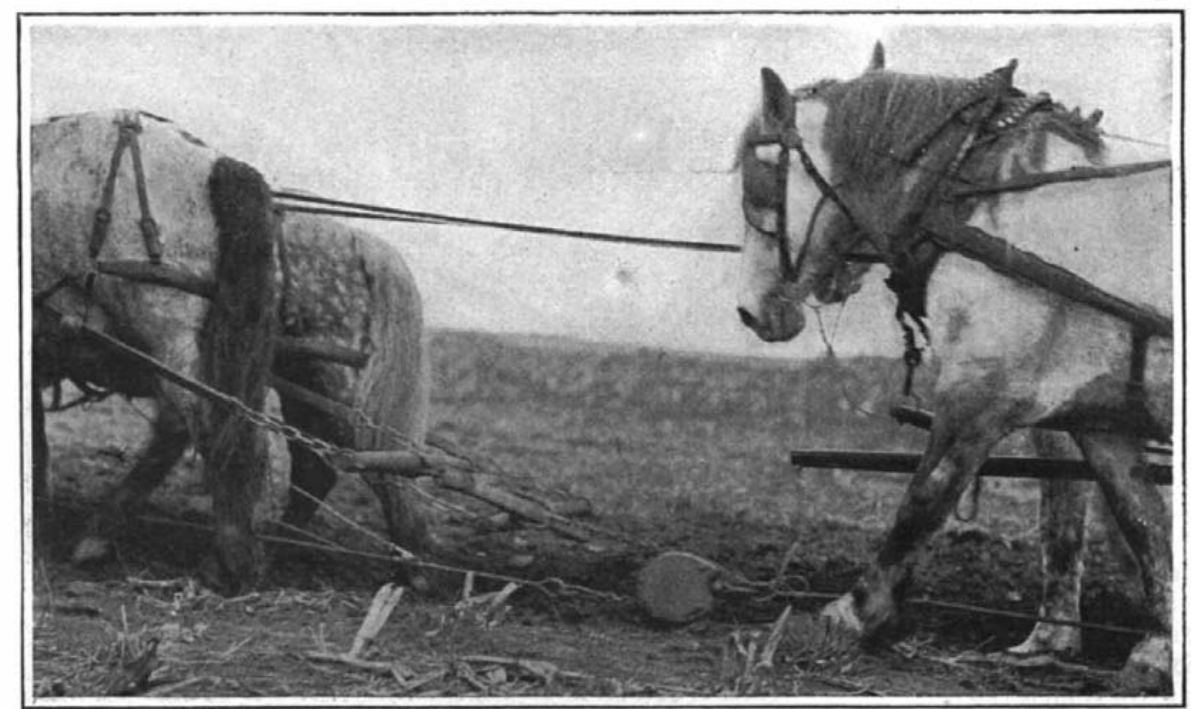

The single pulley-used when one team pulls against only one ahead. Here the pulley must be heavy, to keep the traces at the right angle with the shoulders 